http://doi.org/10.35784/iapgos.2751

\title{
QUALITY OF SATELLITE COMMUNICATION IN SELECTED MOBILE ANDROID SMARTPHONES
}

\author{
Przemysław Falkowski-Gilski \\ Gdansk University of Technology, Faculty of Electronics, Telecommunications and Informatics, Gdansk, Poland
}

Abstract. Today, thanks to mobile devices, satellite communication is available to anyone and everywhere. Gaining information on one's position using GNSS (Global Navigation Satellite Systems), particularly in unknown urban environments, had become an everyday activity. With the widespread of mobile devices, particularly smartphones, each person can obtain information considering his or her location anytime and everywhere. This paper is focused on a study, considering the quality of satellite communication in case of selected mobile terminals. It describes a measurement campaign carried out in varying urban environments, including a set of Android-powered smartphones coming from different manufacturers. Based on this, respective conclusions and remarks are given, which can aid consumers as well as device manufacturers and application developers.

Keywords: mobile applications, mobile communication, satellite communication, satellite navigation systems

\section{DOKLADNOŚĆ KOMUNIKACJI SATELITARNEJ W WYBRANYCH MOBILNYCH SMARTFONACH ANDROID}

\begin{abstract}
Streszczenie. Obecnie, dzięki urządzeniom mobilnym, komunikacja satelitarna jest dostępna dla każdego niezależnie od położenia. Pozyskiwanie informacji o własnej pozycji z wykorzystaniem systemów GNSS (Global Navigation Satellite Systems), szczególnie w nieznanych środowiskach miejskich, stało sie codzienna aktywnościa. Wraz z wszechobecnościa urządzeń mobilnych, w szczególności smartfonów, każda osoba może pozyskać informacje dotyczace jego lub jej położenia zawsze $i$ wszędzie. Praca ta skupia się na badaniu, dotyczacym jakości komunikacji satelitarnej w przypadku wybranych terminali mobilnych. Opisuje kampanię pomiarowa przeprowadzona $w$ zmiennym środowisku miejskim, z wykorzystaniem zestawu smartfonów pracujacych pod kontrola systemu Android pochodzacych od różnych dostawców. Na podstawie tego wyciagnięto wnioski i wskazówki, które moga wspomóc zarówno konsumentów jak i producentów sprzętu i programistów aplikacji.
\end{abstract}

Słowa kluczowe: aplikacje mobilne, komunikacja mobilna, komunikacja satelitarna, systemy nawigacji satelitarnej

\section{Introduction}

Due to the technological development, mobile terminals have evolved into functionally-sophisticated devices, such as smartphones. The Android platform has become one of the most popular operating system, with millions of new users each year. At present, there is a growing demand for positioning services, ranging from pedestrian navigation to consumer behavior analysis. These systems have been successfully used in many applications and have become very popular in recent years. A review of selected wireless positioning solutions, operating in both indoor and outdoor environments, including fundamentals of positioning techniques, methods, systems, as well as information processing mechanisms, may be found in [9].

\section{Positioning and Navigation with Mobile Devices}

Most often, the 2.4 and $5 \mathrm{GHz}$ band, utilized by Bluetooth and $\mathrm{Wi}$-Fi devices, is also used for indoor and/or outdoor (together with GNSS) navigation purposes. An analysis of the positioning accuracy in the aforementioned band, along with a comparison of indoor and outdoor navigation techniques, for selected ISM (Industrial, Scientific and Medical) bands, is available in [5].

Currently, many solutions make use of the RSSI (Received Signal Strength Indicator) parameter, most often related to beacons. An analysis of localization performance, concerning BLE (Bluetooth Low Energy) for tracking the movement of individuals, e.g. in order to indicate popular paths in an interactive art installation, is available in [1].

Other researchers focus on RFID (Radio-Frequency Identification) tags, e.g. a three-dimensional indoor positioning system based on a multiple trilateration algorithm [12]. Whereas some utilize UWB (Ultra Wideband) technology, mainly due to the fact that UWB signals are well-suited for communication and tracking systems, as they provide increased tolerance to localization errors due to the finite time resolution of the transmitted pulses and their large bandwidth. An investigation of UWB and hybrid-UWB schemes may be found in [2].

As shown, mobile navigation along with positioning technologies can lead to the development of various services, such as: disaster recovery, content delivery, and efficient point-to-point communication. As a result, different algorithms and techniques have been developed, in order to minimize the localization error.

In [6] authors investigated the performance of mobile personal positioning devices, utilized for pedestrian navigation in urban environments. They focused mainly on blind and visually impaired individuals. Due to the fact that GNSS-based devices suffer from a decrease in accuracy in urbanized areas, related to frequent NLOS (Non-Line-of-Sight) conditions, particularly in the vicinity of multistory buildings and other man-made objects. Thanks to a hybrid GPS-Galileo module, authors developed a prototype system in order to improve the comfort of everyday life.

Another group of authors [11] investigated a method of tracing massive amounts of people and providing them with visual information. This system was based on the HAIP (High Accuracy Indoor Positioning) technology by Nokia. The aforementioned studies inspired this one, considering the quality of satellite communication among popular consumer devices, namely smartphones.

\section{About the study}

Due to the widespread and mobility of portable devices, it seemed interesting to investigate the precision that modern smartphones can offer. Particularly, what is the quality of satellite positioning and navigation systems for urban mobility applications. That is why this study, concerning Android-powered terminals, was carried out.

\subsection{Tested mobile device}

The study was carried out using two mobile devices, particularly smartphones, released to the market in 2019. They came from different manufacturers, and are further labeled as smartphone 1 and smartphone 2 .

The first one had an 8-core CPU $(2.2 \mathrm{GHz}), 3 \mathrm{~GB}$ of RAM, and was powered by Android Pie (9.0). The integrated GNSS module was compatible with GPS, GLONASS, Galileo, BeiDou, and QZSS.

The second device had also an 8-core CPU (2.3 GHz), 4 GB of RAM, and was powered by Android Pie (9.0). The integrated GNSS module was compatible with GPS, GLONASS, Galileo, and BeiDou. 


\subsection{Tested scenarios}

In the first scenario, the route resembled a square. It was evaluated with a bicycle at an average speed of $8 \mathrm{~km} / \mathrm{h}$, and a car at an average speed of $35 \mathrm{~km} / \mathrm{h}$. This route went along 3 streets in the city of Gdansk. It varied in type of structure and its closest neighborhood. Some part of it was surrounded by buildings, and some of it was next to an open terrain.

In the second scenario, the route resembled a straight line. As previously, it was evaluated with a bicycle at an average speed of $8 \mathrm{~km} / \mathrm{h}$, and a car at an average speed of $35 \mathrm{~km} / \mathrm{h}$. This route, based on the type of surrounding buildings, could be divided into 2 parts. The first part had high buildings on one side, whereas the second part was an open terrain.

All obtained data were recorded in the raw format [13], and then processed using the GNSS Measurement Tool [14] as well as Matlab software. During both measurement and processing, a custom software was utilized, in order to obtain as much data as possible. The measurement campaign included 2 types of routes (square-shaped and straight line), 2 types of communication means (bicycle - low speed, car - high speed), and of course 2 smartphones.

\section{Obtained results}

To start with, obtained results will be described taking into consideration the type of route (square-shaped and straight line), type of mobility (bicycle and car), and utilized smartphone (smartphone 1 and smartphone 2). Next, obtained results will be compared and discussed.

\section{Square-shaped route - bicycle excursion - smartphone 1}

During this bicycle excursion, as shown in figure 1 , the device observed 39 satellites from 4 constellations: GPS, GLONASS, Galileo, and BeiDou. Among them 29 were monitored (see figure 2), as some were on the outskirts of the horizon. Due to this, signals from those 10 satellites did not reach the reference threshold signal level. The average CNR (Carrier-to-Noise Ratio) for 4 strongest satellites' signal strength was equal to: GPS $-26.8 \mathrm{dBHz}$, GLONASS $-21.8 \mathrm{dBHz}$, Galileo - $22.8 \mathrm{dBHz}$, BeiDou - $28.8 \mathrm{dBHz}$ (best geometry). As shown, the strongest signal was observed for BeiDou.

The signal with the strongest CNR was observed for satellite C27 from the BeiDou constellation. This satellite, like C28 and $\mathrm{C} 22$, was observed only during the first few seconds of measurement. The signal strength from other BeiDou satellites was equal to approx. $20-25 \mathrm{dBHz}$. The signal strength itself was unstable.

\section{Square-shaped route - bicycle excursion - smartphone 2}

In this case, as shown in figure 3 , the smartphone observed 40 satellites, where 22 of them were monitored. It is worth mentioning that signals from 2 GPS satellites were omitted, as well as most of the signals from Galileo and BeiDou systems (see figure 4). The average CNR for 4 strongest satellites' signal strength was equal to: GPS $-38.1 \mathrm{dBHz}$ (best geometry), GLONASS - $36.5 \mathrm{dBHz}$, Galileo - $24.5 \mathrm{dBHz}$, BeiDou $-21.1 \mathrm{dBHz}$.

It should be pointed out that BeiDou and Galileo satellites were not monitored during most of the time. Biases in the clock itself had a significant impact as well.

\section{Square-shaped route - car excursion - smartphone 1}

During this drive, as shown in figure 5, 46 satellites were observed, considering GPS, GLONASS, Gaileo, and BeiDou, 40 of which were monitored (see figure 6). The CNR values did not reach the reference values, which was caused by additional attenuation by the car itself, as the mobile device was located inside of it. The average CNR for 4 strongest satellites' signal strength was equal to: GPS $-34.4 \mathrm{dBHz}$ (best geometry), GLONASS - $29.0 \mathrm{dBHz}$, Galileo - $24.6 \mathrm{dBHz}$, BeiDou - 29.2 dBHz.
During approx. half of the time, the clock was not concise, resulting in a discontinuous time of satellite observation, especially in case of BeiDou and Galileo. The best reception quality was observed for G16, G27, and G20, which were located on more than 45 degree elevation.

\section{Square-shaped route - car excursion - smartphone 2}

In this case, as shown in figure 7, 32 satellites were observed, whereas 18 of them were monitored. Satellites from BeiDou, as well as G29 and G30 from GPS, were omitted, although they were on the 5 th degree of elevation (see figure 8). Additionally, C12 was not monitored, although it was on the highest position. The average CNR for 4 strongest satellites' signal strength was equal to: GPS - $37.7 \mathrm{dBHz}$ (best geometry), GLONASS $-33.8 \mathrm{dBHz}$, BeiDou $-33.9 \mathrm{dBHz}$

\section{Straight line route - bicycle excursion - smartphone 1}

When examining the route shown in figure 9, the device registered 40 satellites, with 30 of them being monitored. They came from GPS, GLONASS, Galileo, and BeiDou constellations. The omitted satellites came from Galileo and BeiDou, and were recorded below the 5 th degree of elevation (see figure 10).

Furthermore, the E02 Galileo satellite was also omitted, although being on the 15 th degree of elevation. The average CNR for 4 strongest satellites' signal strength was equal to: GPS - 34.4 dBHz (best geometry), GLONASS - $29.4 \mathrm{dBHz}$, Galileo $-27.9 \mathrm{dBHz}$, BeiDou $-30.8 \mathrm{dBHz}$.

\section{Straight line route - bicycle excursion - smartphone 2}

In this case, as shown in figure 11 , this device also registered 40 satellites form GPS, GLONASS, Galileo, and BeiDou constellations, from which 31 were monitored (see figure 12). In case of the 3 first systems, they offered stable reception conditions. The average CNR for 4 strongest satellites' signal strength was equal to: GPS $-38.0 \mathrm{dBHz}$ (best geometry), GLONASS - $35.6 \mathrm{dBHz}$, Galileo - $28.4 \mathrm{dBHz}$, BeiDou - 24.4 dBHz.

This mobile device enabled stable reception for GPS and GLONASS constellations. The CNR value did not change much, equal too approx. $38-45 \mathrm{dBHz}$ over time. A degradation in reception quality was observed in case of satellites G18, G11, and G30, which were situated on the 30th degree of elevation.

\section{Straight line route - car excursion - smartphone 1}

In this case, as shown in figure 13, 42 satellites were observed, including GPS, GLONASS, Galileo, and BeiDou constellations, from which 31 were monitored (see figure 14). The average CNR for 4 strongest satellites' signal strength was equal to: GPS $-32.8 \mathrm{dBHz}$ (best geometry), GLONASS - $30.8 \mathrm{dBHz}$, Galileo - $32.5 \mathrm{dBHz}$, BeiDou $-32.5 \mathrm{dBHz}$.

In case of BeiDou, the $\mathrm{C} 19$ satellite exceeded the reference signal level. However, the signal from this satellite was only observed for a limited time period.

\section{Straight line route - car excursion - smartphone 2}

When examining the route shown in figure 15 , this device observed 34 satellites, where 20 of them were monitored. They included GPS, GLONASS, Galileo, BeiDou, and even 1 QZSS (quite surprisingly, although according to the technical specification this constellation was supposed to be not supported). In case of those satellites that were not monitored, 12 of them came from Galileo. All of them had a high elevation, e.g. $\mathrm{C} 12$ was in the zenith, the other 7 on elevation of above 15 degrees. The smartphone did not monitor satellites G30 and G29, which were on elevation below 5 degrees (see figure 16).

The received signal strength values were high, although being recorded inside a car. The average CNR for 4 strongest satellites' signal strength was equal to: GPS $-40.3 \mathrm{dBHz}$ (best geometry), GLONASS - $35.9 \mathrm{dBHz}$, BeiDou (and QZSS) - $33.3 \mathrm{dBHz}$. The received signal strength level was stable, especially when examining GPS satellites at a height of above 30 degrees, i.e. G12. 


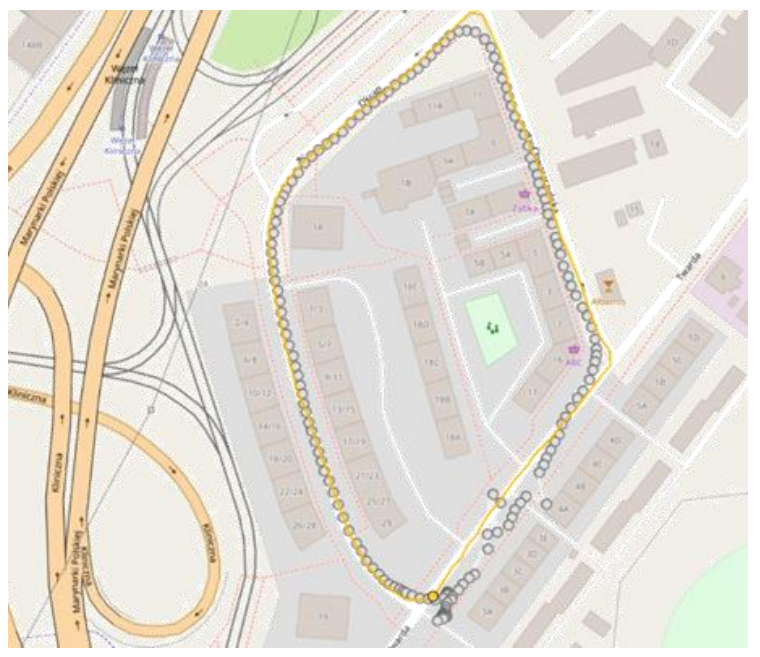

Fig. 1. Bicycle excursion along the square-shaped route with smartphone 1: yellow - real route, dot-measured route

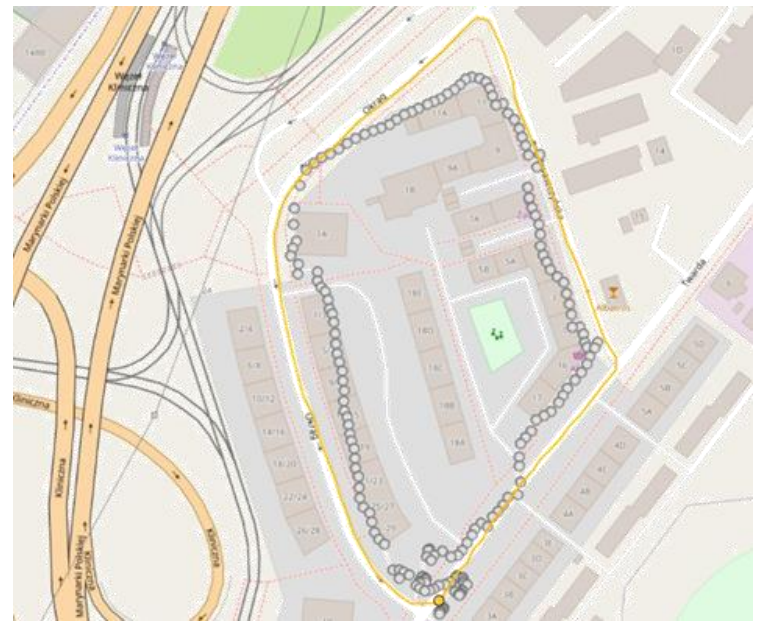

Fig. 3. Bicycle excursion along the square-shaped route with smartphone 2 : yellow - real route, dot-measured route

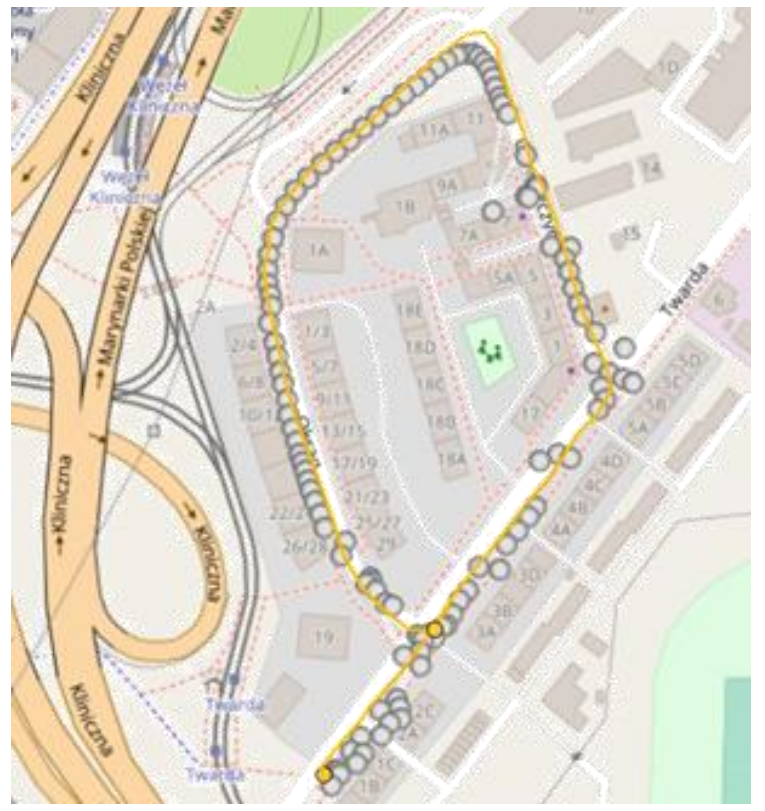

Fig. 5. Car excursion along the square-shaped route with smartphone 1: yellow - real route, dot-measured route

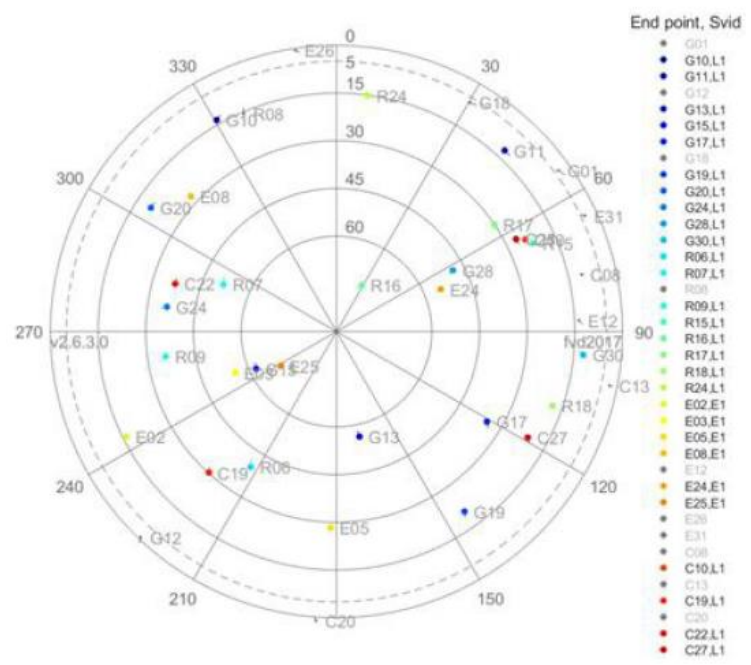

Fig. 2. Observed satellites - bicycle excursion along the square-shaped route with smartphone 1
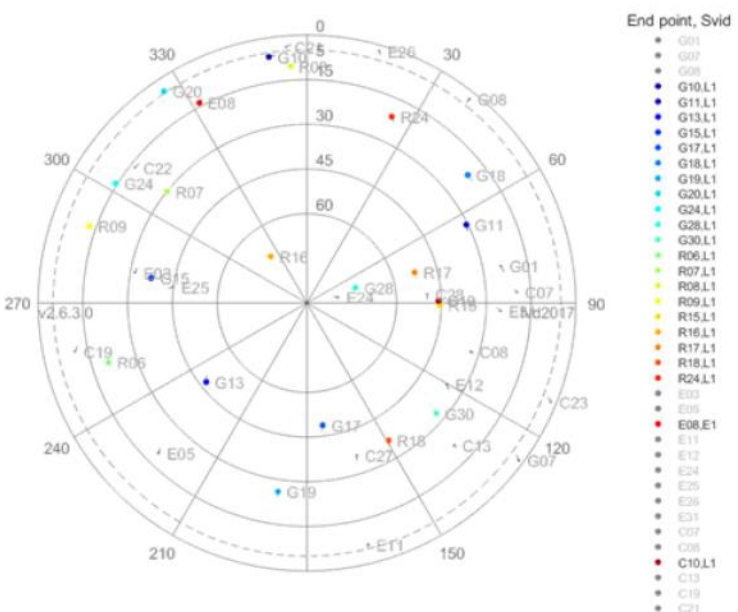

Fig. 4. Observed satellites - bicycle excursion along the square-shaped route with smartphone 2

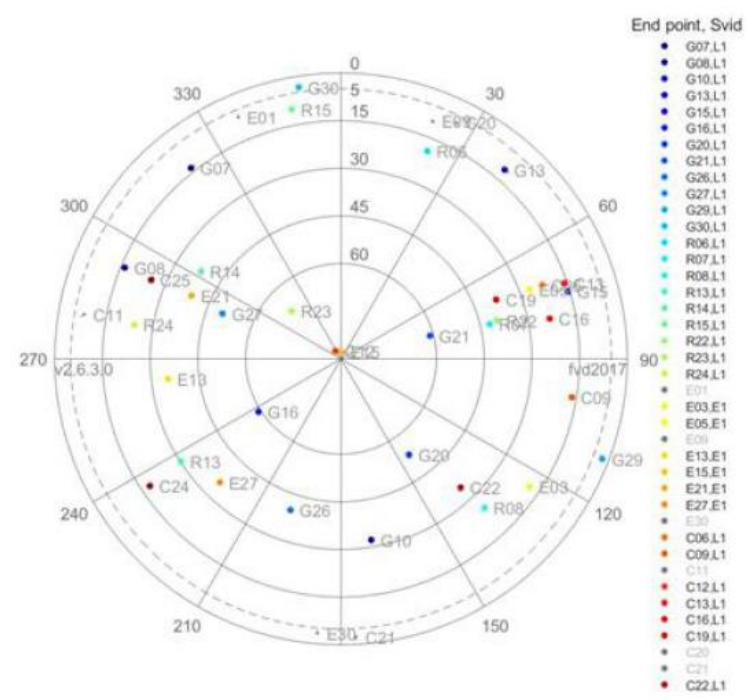

Fig. 6. Observed satellites - car excursion along the square-shaped route with smartphone 1 


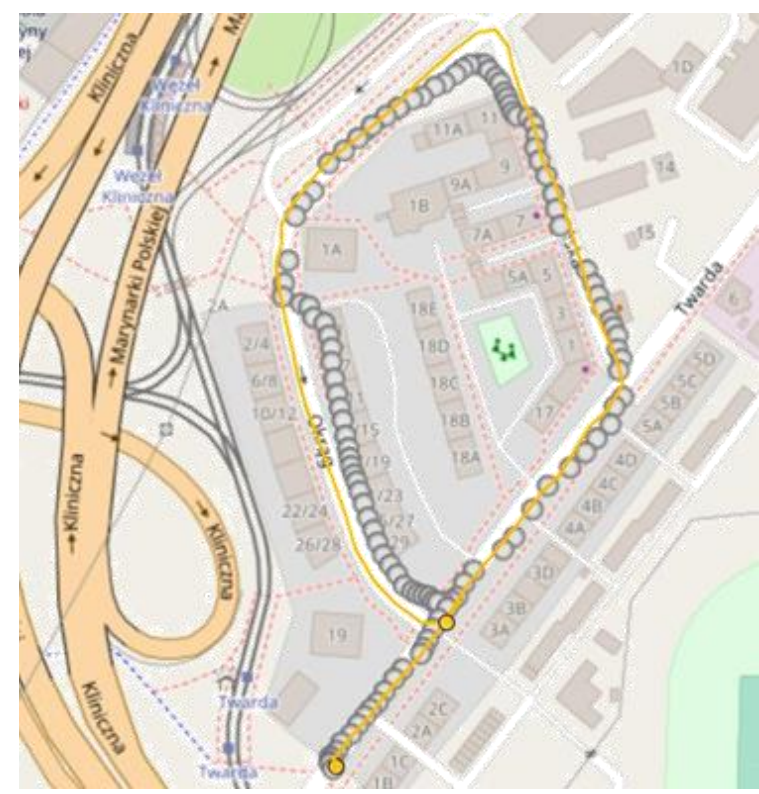

Fig. 7. Car excursion along the square-shaped route with smartphone 2. yellow - real route, dot-measured route

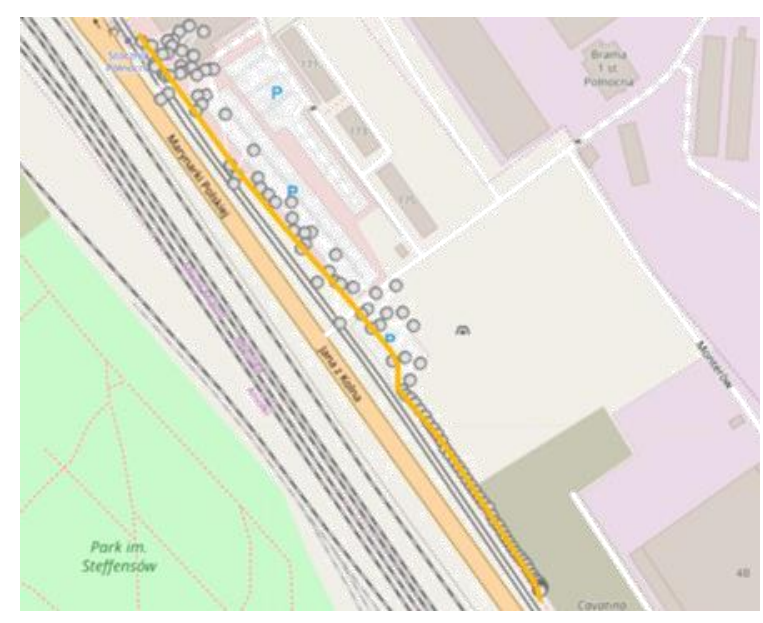

Fig. 9. Car excursion along the straight line route with smartphone 1: yellow - real route, dot-measured route

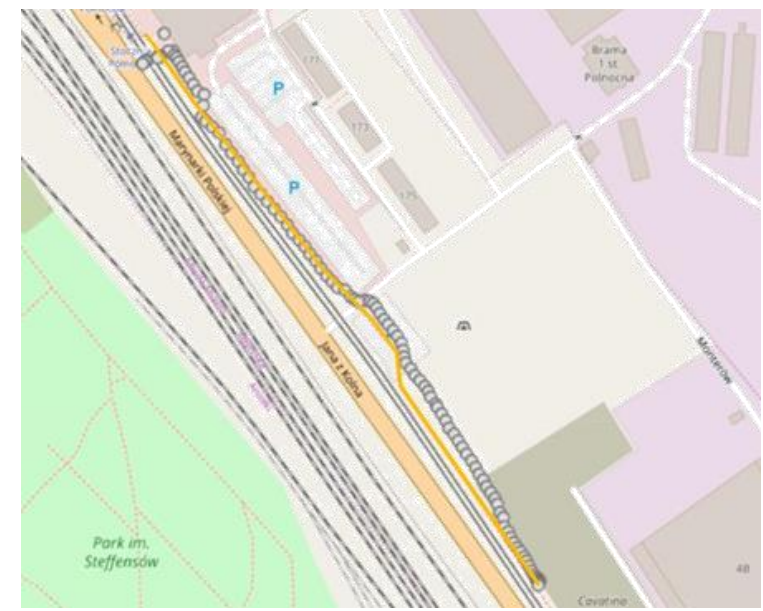

Fig. 11. Bicycle excursion along the straight line route with smartphone 2: yellow - real route, dot-measured route

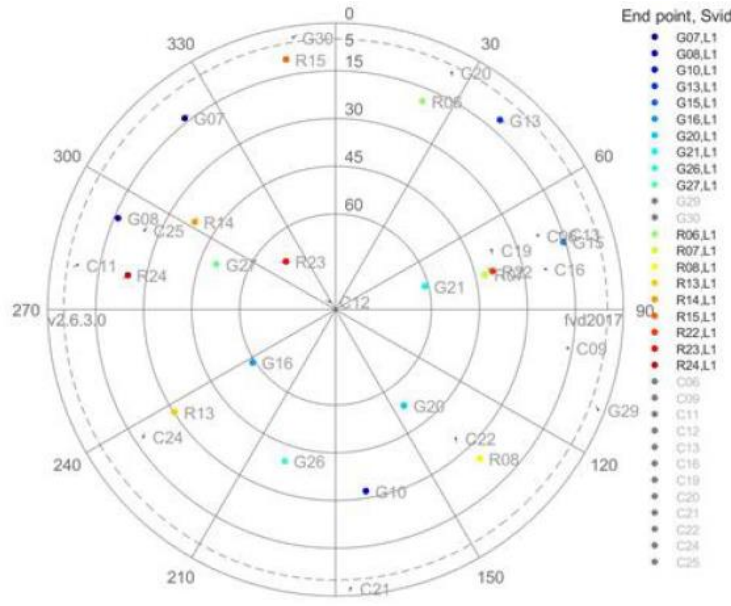

Fig. 8. Observed satellites - car excursion along the square-shaped route with smartphone 2
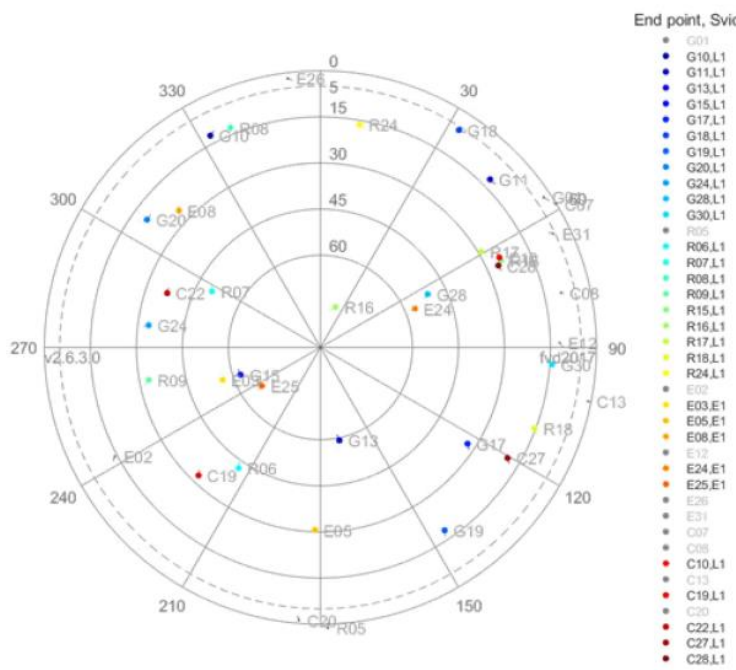

Fig. 10. Observed satellites - bicycle excursion along the straight line route with smartphone 1

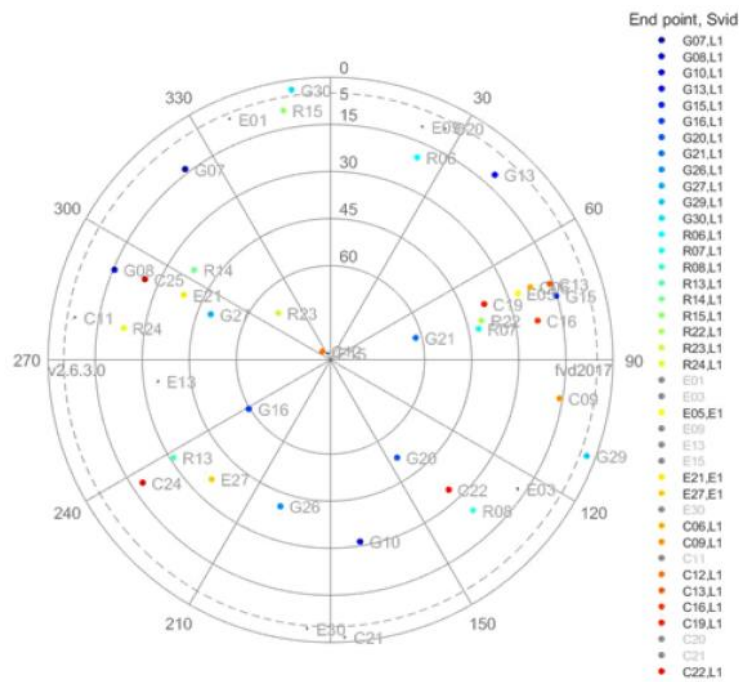

Fig. 12. Observed satellites - bicycle excursion along the straight line route with smartphone 2 


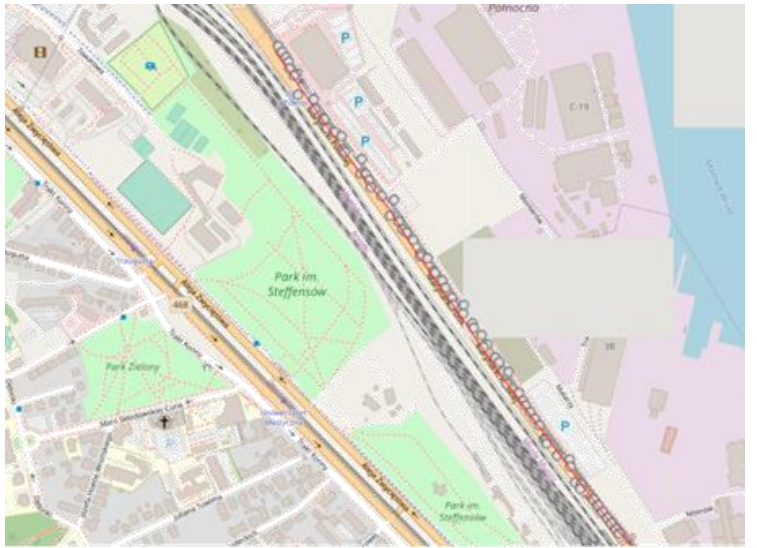

Fig. 13. Car excursion along the straight line route with smartphone 1: yellow - real route, dot-measured route

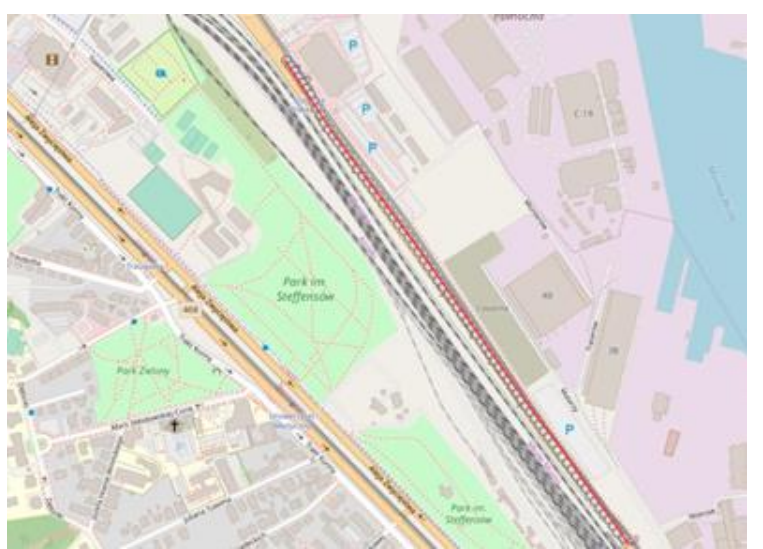

Fig. 15. Car excursion along the straight line route with smartphone 2: yellow - real route, dot-measured route

\section{Summary}

This work describes results of a study, focused on the precision of GNSS systems using smartphones, their quality, reliability, related to signal reception. The tested devices, coming from 2 different manufacturers, were all Android-powered devices operating on version 9.0 (Pie). The measurement campaign itself was carried out in different conditions, including surrounding buildings, terrain topology, and urban fabric.

The devices came from a medium-end segment, most popular among consumers. Although indexed at the same level, considering their quality and price, they proved to be different, e.g. when going along a straight line or taking turns. As a result, obtained results were completely unlike, although tested in the same research scenario. As shown, a number of differentiators had been noticed.

The first differentiator was the number of observed satellites, summarized in table 1 . In case of smartphone 1, the total number of observed satellites (respective signals) was equal to 167, from which 130 were monitored (78\% of all). Whereas smartphone 2 received signals from 146 satellites, from which 91 were monitored $(62 \%$ of all).

This difference is also clearly visible in case of satellite parameters. Satellites with low elevation values were neglected (excluded) by both devices. Additionally, the second device favored GPS and GLONASS constellations. Moreover, surprisingly smartphone 2 recorded a QZSS satellite, although according to the technical specification the build-in components

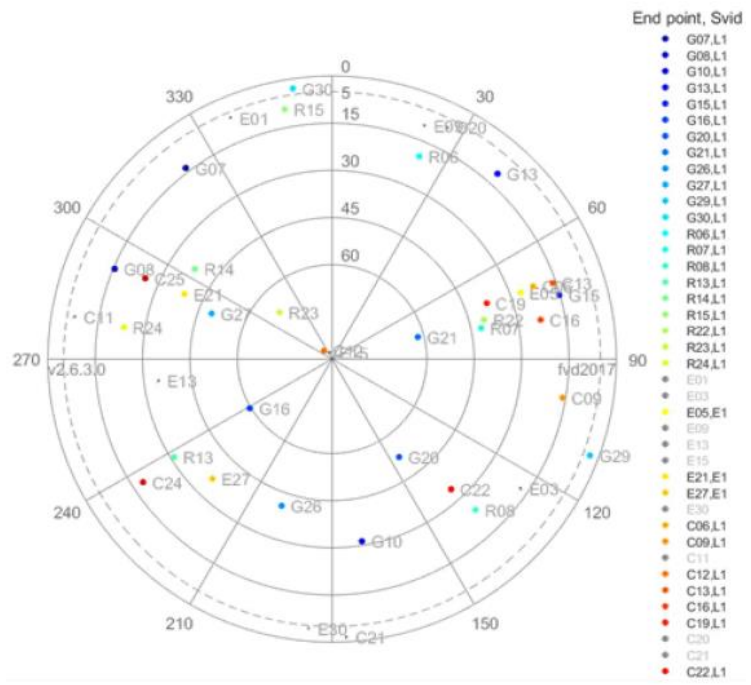

Fig. 14. Observed satellites - car excursion along the straight line route with smartphone 1

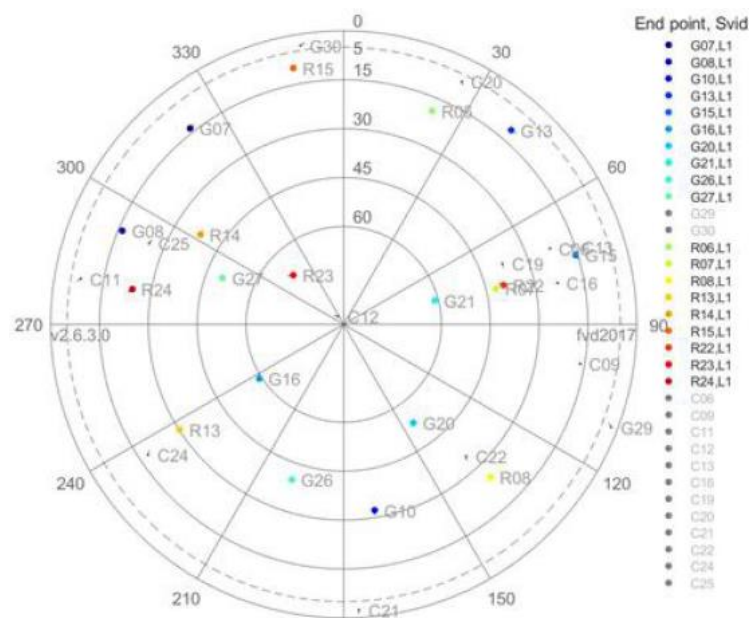

Fig. 16. Observed satellites - car excursion along the straight line route with smartphone 2

were not compatible with this constellation. It should be pointed out that smartphone 1 was compatible with QZSS, and yet it did not observe any of them during the whole study.

Next was the stability of signal reception itself. The first smartphone seldom provided a signal level above the referenced CNR. Whereas the second one received at least over 10 such signals (above reference level), from which only 1 came from a constellation other than GPS or GLONASS.

As the number and availability of smartphones continues to grow, every year new mobile devices, coming from a broad range of manufacturers, emerge on the market. One must note that the type of utilized inner components, and not only screen size or amount of memory, has an enormous impact on the efficiency and quality of operation of a mobile device. Further studies could include a broader range of user devices, types of motion, shape of the path, types of terrain, surroundings (both man-made and natural), urban fabric, etc. Additional information on mobile devices, including consumption of content and quality-related issues, is available in $[3,7,8]$. A source of inspiration for future studies may be found in [10].

Table 1. Number of observed (monitored) satellites

\begin{tabular}{|c|c|c|}
\hline Device & \multicolumn{1}{|c|}{ Square-shaped route } & Straight line route \\
\hline smartphone 1 & $\begin{array}{l}\text { Bicycle excursion: 39(29) } \\
\text { Car excursion: 46(40) }\end{array}$ & $\begin{array}{c}\text { Bicycle excursion: 40(30) } \\
\text { Car excursion: 42(31) }\end{array}$ \\
\hline smartphone 2 & $\begin{array}{l}\text { Bicycle excursion: 40(22) } \\
\text { Car excursion: 32(18) }\end{array}$ & $\begin{array}{c}\text { Bicycle excursion: 40(31) } \\
\text { Car excursion: 34(20) }\end{array}$ \\
\hline
\end{tabular}




\section{References}

[1] Ashby S., Hanna J., Rodrigues R.: Using BLE beacons to simulate proxemic surveillance for an interactive art installation. Proceedings of the 2017 Conference Extended Abstracts on Human Factors in Computing Systems CHI I, 2017, 1486-1493 [http://doi.org/10.1145/3027063.3053096].

[2] Bogdani E., Vouyioukas D., Nomikos N.: Localization error modeling of hybrid fingerprint-based techniques for indoor ultra-wideband systems. Telecommunication Systems 63, 2016, 223-241.

[3] Boz E., Finley B., Oulasvirta A., Kilkki K., Manner J.: Mobile QoE prediction in the field. Pervasive and Mobile Computing 59, 2019, 101039.

[4] Chruszczyk Ł., Zając A., Grzechca D.: Comparison of 2.4 and 5 GHz WLAN network for purpose of indoor and outdoor location. International Journal of Electronics and Telecommunications 62(1), 2016, 71-79.

[5] Chruszczyk Ł., Zając A.: Comparison of indoor/outdoor, RSSI-based positioning using 433, 868 or $2400 \mathrm{MHz}$ ISM bands. International Journal of Electronics and Telecomunications 62(4), 2016, 395-399.

[6] Drypczewski K., Moszyński M., Demkowicz J., Bikonis K., Stepnowski A.: Design of the dual constellation GPS/GALILEO mobile device for improving navigation of the visually impaired in an urban area. Polish Maritime Research 22, 2015, 15-20 [http://doi.org/10.1515/pomr-2015-0065].

[7] Falkowski-Gilski P., Uhl T.: Current trends in consumption of multimedia content using online streaming platforms: a user-centric survey. Computer Science Review 37, 2020, 100268.

[8] Falkowski-Gilski P.: On the consumption of multimedia content using mobile devices: a year to year user case study. Archives of Acoustics 45(2) 2020, 321-328 [http://doi.org/10.24425/aoa.2020.133152].

[9] Gilski P., Stefański J.: Survey of radio navigation systems. International Journal of Electronics and Telecommunications 61(1), 2015, 43-48.

[10] Jeena Jacob I., Kolandapalayam Shanmugam S., Piramuthu S., Falkowski-Gilski P. (Eds.): Data intelligence and cognitive informatics: proceedings of ICDICI 2020. Springer, Singapore 2021.
[11] Ryu A., Nelson M., Mehtala A., Nyberg T., Xiong G.: Non-GPS positioning sensor network in social manufacturing. Proceedings of the 2016 IEEE International Conference on Service Operations and Logistics, and Informatics SOLI I, 2016, 47-52 [http://doi.org/10.1109/SOLI.2016.7551660].

[12] Xu H., Ding Y., Wang R., Shen W., Li P.: A novel radio frequency identification threedimensional indoor positioning system based on trilateral positioning algorithm. Journal of Algorithms and Computational Technology 10(3), 2016, 158-168 [http://doi.org/10.1177/1748301816649078].

[13] https://developer.android.com/guide/topics/sensors/gnss.html (available: 7.09.2021).

[14] https://github.com/google/gps-measurement-tools (available: 07.09.2021).

\section{Ph.D. Przemysław Falkowski-Gilski}

e-mail: przemyslaw.falkowski@eti.pg.edu.pl

Przemysław Falkowski-Gilski is a graduate of the Faculty of Electronics, Telecommunications and Informatics (ETI), Gdansk University of Technology. Currently he works as an assistant professor.

Member of a number of organizational, scientific, technical and program committees of national and international conferences, as well as a reviewe in numerous Polish and English-language journals.

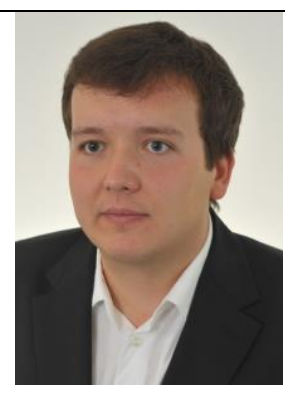

http://orcid.org/0000-0001-8920-6969

otrzymano/received: $20.09 .2021 \quad$ przyjęto do druku/accepted: 15.12 .2021 